\title{
QRA Considering Multi-Vessel Failure Scenarios due to a Natural Disaster - Lessons from Fukushima
}

\author{
Heetae Kim ${ }^{\mathrm{a}}$, Gyunyoung Heo ${ }^{\mathrm{b}}$, Seungho Jung ${ }^{\mathrm{a}^{*}}$ \\ ${ }^{a}$ Department of Environmental and Safety Engineering, Ajou University, Su-won, Gyeonggi-do, \\ 443-749, Republic of Korea \\ ${ }^{b}$ Department of Nuclear Engineering, Kyung Hee University, Yong-in, Gyeonggi-do, 446-701, \\ Republic of Korea
}

The Fukushima accident is the largest nuclear power plant accident caused by a natural disaster, which shut off the cooling system. In this accident, an initiating event from a single unit was propagated to other units at the site. Prior to the Fukushima accident, scenarios for multi-unit failures had been screened out, so that only single unit failure scenarios were taken into account in the nuclear industry. Since that accident, the nuclear industry in South Korea is now more concerned with multi-unit Probabilistic Safety Assessment (PSA) and is attempting to develop a new methodology since there are generally more than four units on one site in the country

The chemical and petrochemical industries have experienced a number of incidents/accidents related to multi-units such as vessels and tanks because many of these units are usually installed on a site. The chemical industry has a wide range of experience, but most scenarios have involved domino effects, while the study of multi-vessel accidents caused by natural disasters (i.e., earthquakes) is lacking. The purpose of this paper is to review past experiences in the chemical industry and adapt appropriate process safety applications using risk analysis related to multiple vessels (tanks) at a site. Several QRA approaches have been searched and employed to compare the risks of some chemical plant complexes in South Korea regarding multi-vessel (unit) failure scenarios due to natural disasters.

\section{Introduction}

The Fukushima Daiichi accident has had a significant impact on the nuclear industry and was the third core damage accident to occur since the birth of commercial nuclear power. The major difference compared with other severe accidents was the fact that the initiating event from a single unit was propagated to other multiple units. A series of critical events had to be dealt with simultaneously, and each event was tied to the previous events. A so-called domino effect was clearly shown when the nearly completed and temporarily installed ad hoc external power line to 
\#2 unit was damaged by a hydrogen explosion of the neighboring \#1 unit owing to the dissociation of zirconium. This damage resulted in a delay in activating the emergency responses required to cope with the problems at hand.

Existing probabilistic safety assessment (PSA) models have screened out multiple unit accidents due to their extremely low frequency, and have focused solely on single-unit events. In fact, a large number of nuclear sites have more than two units. In South Korea, there are up to ten units at the same site. As observed in the Fukushima case, a multi-unit accident has a higher amount of risk and requires a multi-unit related PSA framework for a risk assessment, which requires properly addressing the technical issues. Starting from 1978, operating plants in Korea have been located in four different sites, Kori, Hanbit, Hanul, and Wolseong, and a few multiplant events have occurred, as shown in Table 1.

Table 1. Event list of multiple plants in Korea

\begin{tabular}{|c|c|c|c|}
\hline Plant & Year & Category & Overview of Accident \\
\hline $\begin{array}{l}\text { Kori } \\
1-4\end{array}$ & 1987 & $\begin{array}{l}\text { Loop (Loss of } \\
\text { Off-site Power) } \\
\text { due to external } \\
\text { event }\end{array}$ & $\begin{array}{l}\text { Typhoon Thelma caused disturbances in the transmission } \\
\text { systems and let solid waste into the intakes. The nuclear } \\
\text { reactors were consequently stopped. }\end{array}$ \\
\hline $\begin{array}{l}\text { Kori } \\
1-4\end{array}$ & 2003 & $\begin{array}{l}\text { Loop due to } \\
\text { external event }\end{array}$ & $\begin{array}{l}\text { Typhoon Maemi damaged transmission lines. Protective } \\
\text { relays of the plants were operated to the stop nuclear } \\
\text { reactors. }\end{array}$ \\
\hline $\begin{array}{l}\text { Hanul } \\
1 \& 2\end{array}$ & 1997 & LOOP & $\begin{array}{l}\text { During normal operation under full power, heavy snow and } \\
\text { strong winds in the Yeongdong area forced transmission } \\
\text { lines between Uljin and Donghae to gradually undergo } \\
\text { ground faults. }\end{array}$ \\
\hline $\begin{array}{l}\text { Hanul } \\
1 \& 2\end{array}$ & $\begin{array}{l}1997, \\
2006\end{array}$ & $\begin{array}{l}\text { LOUHS } \\
\text { (Loss of Ultimate } \\
\text { Heat Sink) }\end{array}$ & $\begin{array}{l}\text { During normal output operation, a large amount of marine } \\
\text { organisms were flown into the intakes, which settled on the } \\
\text { surface of the drum screens. Differential pressure signals } \\
\text { ordered auto-stops to the circulating water pumps. }\end{array}$ \\
\hline
\end{tabular}

As previously described, it is thought that the risk of a multi-unit plant accident caused by the dependencies among the different units is small based on the design characteristics of domestic Korean nuclear power plants. The two initiating events selected from the case study analysis also occurred from external factors rather than through a randomness of the systems; in addition, event cases of a reactor shutdown caused by a typhoon also exist. Therefore, in the case of Korea, the analysis should be focused on events caused by external hazards (e.g., an earthquake, a tsunami, a super typhoon, strong winds, or rainfall).

On the other hand, a chemical plant is an industrial process plant producing chemicals at a large scale. Chemical plants have specifications of a relatively complex control system and store large amounts of chemicals that can cause an incident, including fires, explosions, and toxic releases. More importantly, chemical plants have multiple vessels that may hold reactive, flammable, and/or toxic materials. We understand that differences between a nuclear reactor and a chemical reactor exist. A chemical reactor is usually made up of a single wall of stainless steel and is significantly smaller than a nuclear reactor. Although accident prevention in a chemical plant is 
important, consequence analyses in chemical plants have been focused upon more than in the nuclear industry. For instance, a propagation of incidents resulting in one vessel exploding followed by another vessel exploding is a typical occurrence in a chemical plant and has been deeply researched; however, it is difficult to think of the same type of domino effect occurring between nuclear reactors owing to their individual strengths. Nonetheless, we have searched through many different incidents and risk assessment methodologies of the chemical industry, which have experienced a number of incidents/accidents related to multiple units such as multiple vessels and tanks because many such units are often installed at a single site. Accidents caused by a natural disaster such as an earthquake are a major concern in the chemical industry as well. As shown in Table 2, representative cases of multi-unit accidents occurring in chemical plants after an earthquake and a subsequent domino effect do exist. Four such accidents were caused from earthquakes and two other incidents were caused solely through a domino effect after the initial explosions.

Table 2. Notable multi-unit accidents after an earthquake and subsequent domino effect

\begin{tabular}{lllll}
\hline Location & Year & $\begin{array}{l}\text { Magnit } \\
\text { ude }\end{array}$ & $\begin{array}{l}\text { Number of } \\
\text { damaged tanks }\end{array}$ & Note \\
\hline $\begin{array}{l}\text { Niigata, } \\
\text { (Japan) }\end{array}$ & 1964 & 7.5 & 5 & Earthquake and domino effect \\
$\begin{array}{l}\text { Miyagi } \\
\text { (Japan) }\end{array}$ & 1978 & 7.7 & 3 & Earthquake, 14 tanks with minor damage \\
$\begin{array}{l}\text { Izmit } \\
\text { (Turkey) }\end{array}$ & 1999 & 7.4 & 6 & $\begin{array}{l}\text { Earthquake, } 10 \text { to } 20 \text { tanks with minor } \\
\text { damage }\end{array}$ \\
$\begin{array}{l}\text { Hokkaido } \\
\text { (Japan) }\end{array}$ & 2003 & 8.3 & 29 & $\begin{array}{l}\text { Earthquake } \\
\begin{array}{l}\text { Mexico city } \\
\text { (Mexico) }\end{array}\end{array}$ \\
$\begin{array}{l}\text { Buncefiled } \\
\text { (UK) }\end{array}$ & 2005 & N/A & 6 large & Domino effect \\
\hline
\end{tabular}

Because substantial accidents from such events have actually occurred, the study of accident cases and risk assessments regarding earthquakes and a subsequent domino effect for multivessel failures in the chemical industry is very important. For this paper, risk assessment methodologies were reviewed to determine what if anything there is to learn from such an endeavor, and a QRA study addressing such methodologies was finally conducted.

In the chemical plant industry, accidents caused by earthquakes are important because they can lead to a domino effect. The combination of an earthquake and a subsequent domino effect has been an issue, and a few researchers have suggested how to integrate such events. A domino event is defined as an event within a chain of events (accident scenarios) that contributes to the domino effect. An incident escalation is a process promoting the degradation of any property as well as injury to people during the development of the domino effect, which tends to increase the amount of damage. Therefore, any event spreading from the equipment, from one industrial unit to another, or from one site to another, should be classified as a domino event. To combine an earthquake and subsequent domino effect within a risk assessment, the initial incident frequency caused by the earthquake should be obtained. Salzano et al. investigated how to calculate the probability of a vessel rupture or damage from the peak ground acceleration (PGA) depending on 
the types of vessels. The group used a historical earthquake frequency with the PGA within a particular province, and obtained the rupture frequency. Once the initial frequency was obtained, the next step was to determine how to properly add the frequency and consequences from the domino effect. It is clear that an accident with a domino effect is very complex and that the chain of events can take on various forms. Fig. 1 shows the complexity of a domino effect.

The dark arrows indicate that the propagation to a secondary unit can be influenced by both the escalation vector from the primary event, and from another secondary event. Also, it is defined that two main features for escalation of domino accident characteristics: direct escalation, indirect escalation. A direct escalation is caused by an immediate exposure of radiation, overpressure, or a fragment projection following an initiating event, which in turn may lead to a secondary accident.

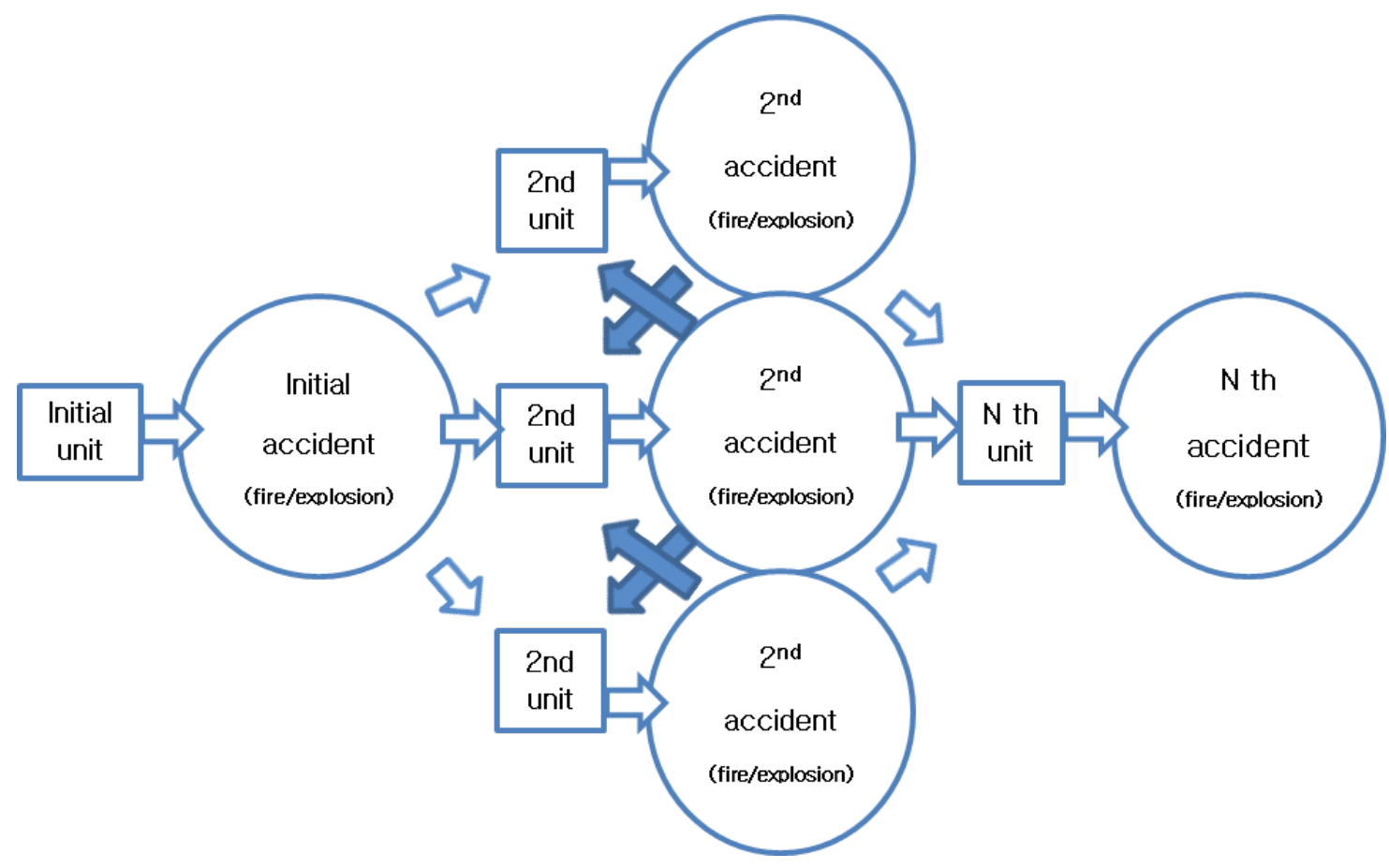

Fig. 1. Principle structures in a chain of accidents (courtesy for reproduced from Loof. et al.)

An indirect escalation can be defined as an escalation of a primary event in which the secondary scenarios are not caused by direct damage to the equipment such as in a direct escalation. Loss of control through the loss of communication, inadequate access to emergency locations from road damage, and damage to structures (support structures or warehouses) can be identified as the most likely mechanisms.

In this paper, only a direct escalation is considered for a QRA study on an LPG site where 11 storage tanks are located in the same proximity. Due to sensitivity regarding $\mathrm{N}$ numbers of calculated FN curves in the city under investigation, the name of the location and the exact $\mathrm{N}$ numbers are all hidden.

\section{Methodology}

This study aims to combine an earthquake with the subsequent domino effect to see the 
increment of consequence as well as frequency through a safety analysis. Several QRA approaches applied to the chemical industry have been searched through and employed to compare the risks of certain chemical plant complexes in South Korea regarding multi-vessel (unit) failure scenarios from seismic events. The suggested approach consists of the following steps:

Table 3. Risk assessment of a domino effect started from a seismic event

\#1. Risk assessment without considering the seismic event and domino effect

\#2. Identification of reference scenarios for the PGA

\#3. Estimation of accident frequency for a given PGA

\#4. Frequency calculation for each combination

\#5. FN curve compared with the calculated consequences for each combination

For \#1, a pervious QRA study was adopted to develop QRA studies on seismic events and their subsequent domino effect. A previous QRA study was conducted for 11 real LPG tanks, as shown in Fig 2. The descriptions of each tank and their rupture frequencies are illustrated in Table 4.

Table 4. Description of tanks

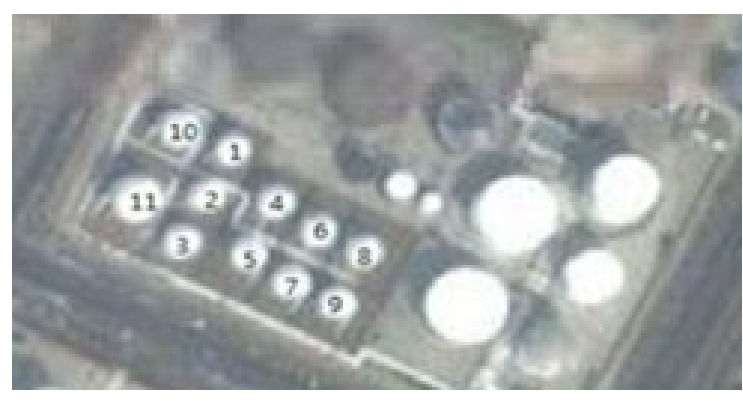

Fig. 2. Layout of 11 tanks

\begin{tabular}{cccc}
\hline \hline $\begin{array}{l}\text { Tank } \\
\#(\mathrm{i})\end{array}$ & Material & $\begin{array}{l}\text { Quantity } \\
\text { (tons) }\end{array}$ & $\begin{array}{l}\text { Generic } \\
\text { rupture } \\
\text { frequency/year }\end{array}$ \\
\hline $1-9$ & Propane & 645 & $1.00 \mathrm{E}-6$ \\
10 & Butane & 1,116 & $1.00 \mathrm{E}-6$ \\
11 & Butane & 2,232 & $1.00 \mathrm{E}-6$
\end{tabular}

It is important to select the original QRA study carefully because the latter works compare the results with the original QRAs, which do not consider seismic events or a domino effect. The original QRA study assumed as its accident scenarios the catastrophic ruptures of 11 tanks with 8,100 people present in the surrounding city, 
as shown in Fig. 3. This population is evenly distributed throughout the city, as shown in the figure. The original study did not take any preventions or mitigations into account, and the resulting FN curve was reproduced using Phast-Risk 6.7, as shown in Fig. 4.

$\uparrow$

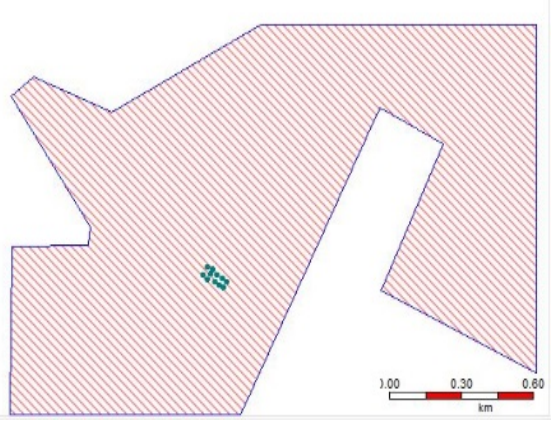

Fig. 3. Population polygon of the nearby city area with the 11 tanks in the center

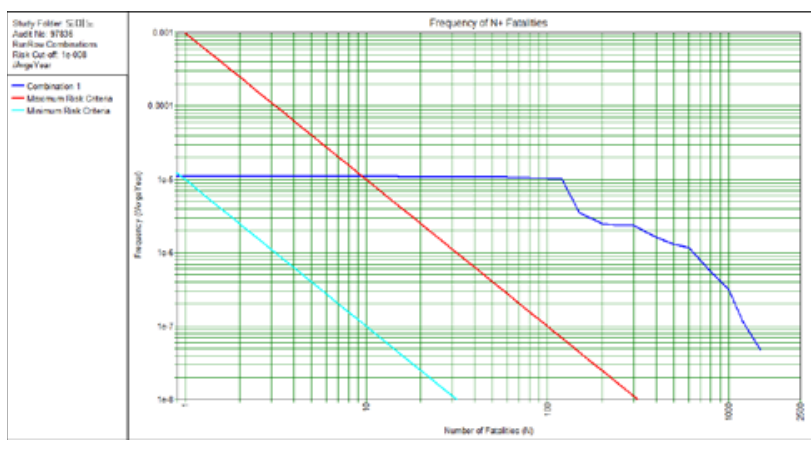

Fig. 4. FN curve for the original QRA study

According to a previous study, several thousand people will lose their lives, with an accumulated frequency of $1.1 \times 10^{-5}$ /year when assuming that each of the 11 tanks has a $10^{-6}$ /year rupture frequency under this catastrophic scenario.

To address procedures \#2 and \#3 in Table 3, the PGA was considered as the ground motion intensity measure owing to the nature of the damage database used. Other researchers have worked on a probabilistic seismic hazard analysis and a vulnerability review, which are described in the following section.

Cozzani et al. produced probit equations on the PGA value for each type of tank. In this study, only pressurized vessels are included in the scenario, and the third equation in Table 5 is mainly used.

Table 5. Probit equations for equipment with seismic fragility (courtesy reproduced from Cozzani et al., 2006)

\begin{tabular}{llll}
\hline \hline Scenario & Target & Probit equation & Dose, D \\
\hline Seismic event & Atmosph.. Storage unanchored & $\mathrm{Y}=-0.833+1.25 \ln (\mathrm{D})$ & PGA \\
Seismic event & Atmosph.. Storage anchored & $\mathrm{Y}=-2.43+1.54 \ln (\mathrm{D})$ & PGA \\
Seismic event & Pressurized Storage, any & $\mathrm{Y}=5.146+0.884 \ln (\mathrm{D})$ & PGA \\
\hline
\end{tabular}

For the location, PGA data were previously suggested in Choi et al., and are directly used in this paper, as shown in Fig 5. 


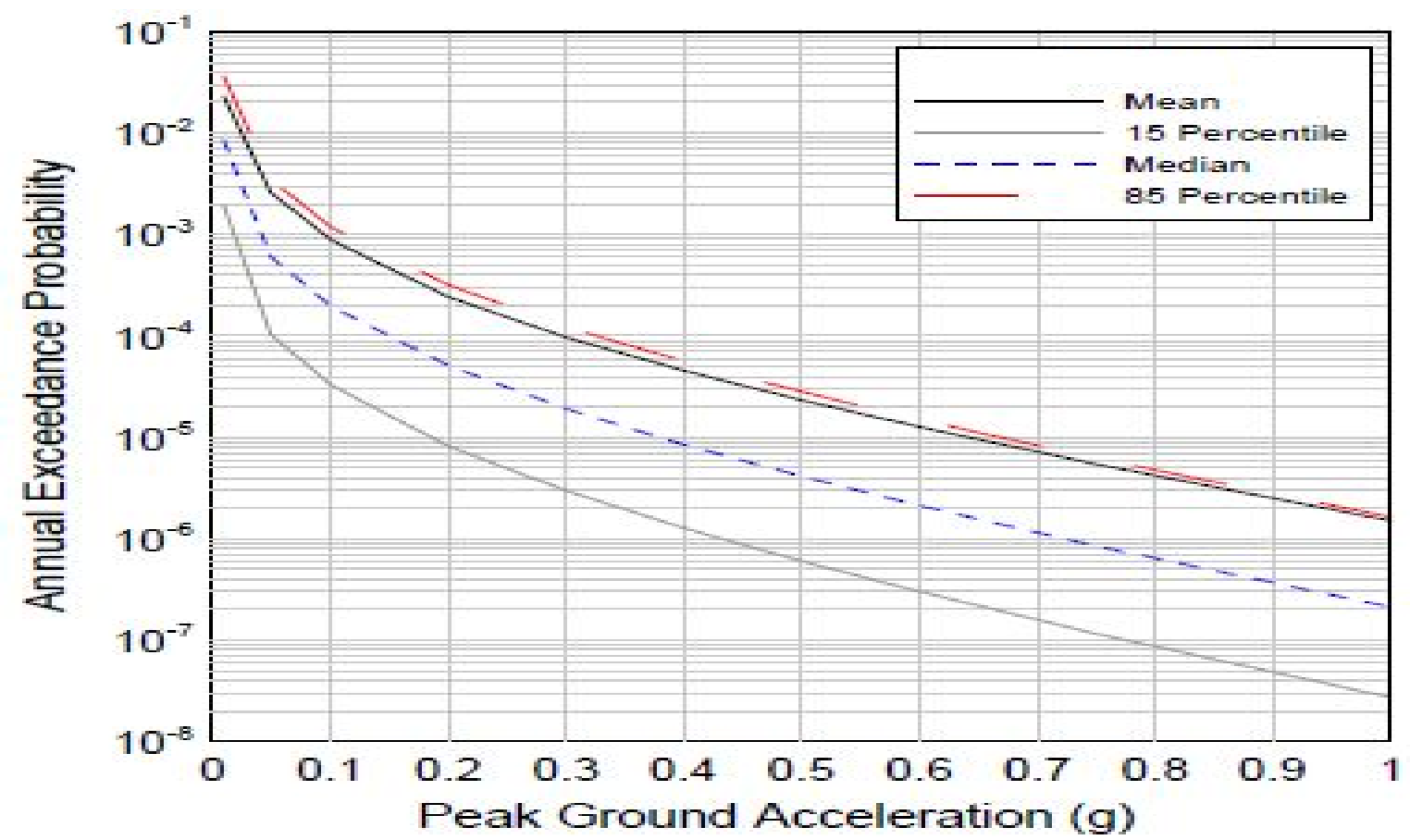

Fig. 5. Annual exceedance probability for PGA at the province (courtesy copied from Choi et al.)

For procedure \#4, the arbitrary probability of an event propagating to the next tank is assumed to be $30 \%$, which assumes that each catastrophic rupture has an immediate ignition_(BLEVE) probability of $30 \%$ based on a general event tree analysis. The remaining $70 \%$ probability is assumed to be dispersion followed by a flash fire. Fig. 6 describes how a failure starting from tank \#1 can propagate to the next immediate tanks (\#2, \#4, and \#10). In the second domino effect, tanks \#2, \#4, and \#10 are again included if they have not failed from the explosion from the first domino effect. This example only shows the domino effect from the failure of tank \#1; however, all of the other initiated failures propagate as well and are summed for the next step. It is thought that a seismic event causes only one tank failure as the initiating event.

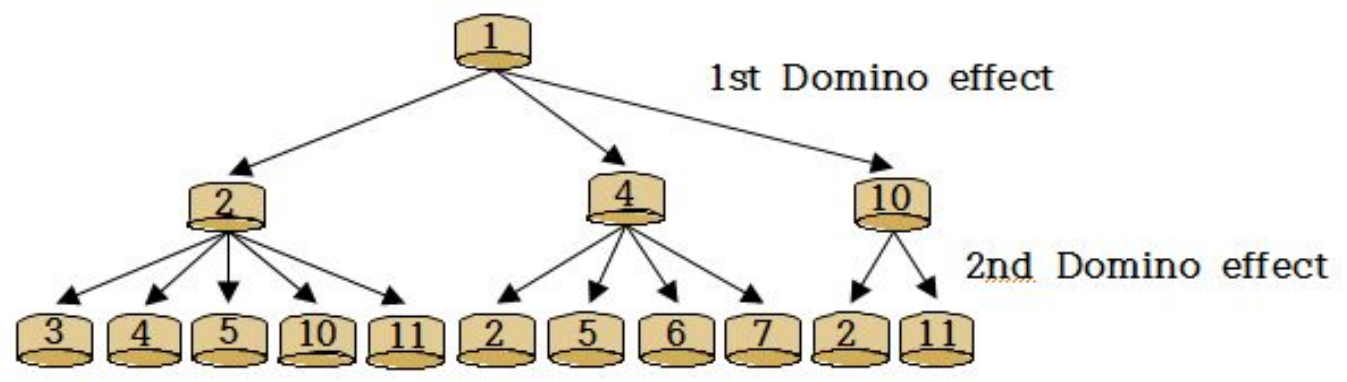

Fig. 6. Example sequence of a domino effect starting from tank \#1

Finally, in step \#5, the increase in incident frequency for each tank after a domino effect starts from any of the tank is used. Starting from each single-tank rupture, different propagations were considered and occasionally a propagation chain was shown to have a different number of fatalities because its impact area may be increased. However, the increase in fatalities is very small because the increase in the size of the fatality zone from the first and second domino 
effects is not large owing to the proximity between tanks. The increased frequencies reflecting all event propagations were inserted into the Phast-Risk assessment.

\section{Results and discussions}

A catastrophic rupture frequency for a tank, $i$, is shown in eqn. (1), and is the sum of the generic rupture frequency and the rupture frequency from a seismic event at the province.

$$
\mathrm{S}=\alpha+A E P_{l} \times \mathrm{P}_{l}
$$

where $\alpha$ is the generic rupture frequency of $10^{-6} /$ year, and $A E P_{l}$ is the annual exceedance probability of the PGA at location $l$, and $\mathrm{P}_{l}$ is the tank rupture probability for the PGA. For instance, AEP is $5 \times 10^{-7} /$ year when the PGA is $0.85 \mathrm{~g}$ at the event location, as shown in Fig. 5 , and $\mathrm{P}_{i}$ is calculated as $50 \%$ using the PGA and the equation in Table 5 for a pressurized vessel. Considering the accumulated rupture frequencies from the domino effects caused from the ruptures of the nearby tanks, as listed in Fig 6, eqn. (2) shows how to calculate the overall frequency based on a domino effect starting from the rupture of a tank after a seismic event.

$$
D_{i}=\sum_{j=1}^{3}\left(E_{j} \times R_{i j}\right) \times\left(A E P_{l} \times P_{l}\right) \quad \text { eqn. (2) }
$$

where $R_{i j}$ is the number of events in which tank i can be affected and ruptured by the $j^{\text {th }}$ domino effect when nearby tanks explode, and $E_{j}$ is the propagation probability for the $j^{\text {th }}$ domino effect. The domino effect frequency, $D_{i}$, is meaningful for a seismic event when $j$ reaches 2 , and thus the third and following domino effects are disregarded owing to their low frequency. Supposing that the domino propagation probability is $0.3, E_{1}$ is 0.3 , and $E_{2}$ is 0.09 . $E_{3}$ does not indicate the third domino effect, but rather the case in which a tank near a ruptured tank initially survives the first domino effect but is affected by the second domino effect. Here, $E_{3}$ is calculated as 0.063 . For instance, tank \#2 in Fig. 6 will not be affected by the first domino effect even though it is near tank \#1, but may be affected by the second domino effect from tanks \#4 and \#10 owing to their proximity. 
All those event numbers are presented in Table 6 where $\mathrm{R}_{\mathrm{ij}}$ are extracted from.

Table 6. Event numbers of ordinal domino effect per tank $\left(R_{i j}\right)$

\begin{tabular}{|c|c|c|c|c|c|c|c|c|c|c|c|}
\hline & \multicolumn{10}{|c|}{ Event number } \\
\hline Tank \# (i) & 1 & 2 & 3 & 4 & 5 & 6 & 7 & 8 & 9 & 10 & 11 \\
\hline \hline $\mathrm{E}_{1}$ & 3 & 6 & 3 & 5 & 5 & 5 & 5 & 3 & 3 & 3 & 3 \\
\hline $\mathrm{E}_{2}$ & 7 & 4 & 7 & 9 & 9 & 4 & 4 & 4 & 4 & 5 & 5 \\
\hline $\mathrm{E}_{3}$ & 4 & 12 & 4 & 10 & 10 & 12 & 12 & 6 & 6 & 4 & 4 \\
\hline
\end{tabular}

Table 7 shows the total rupture frequencies for each tank from a domino effect initiating from a seismic event. As shown, tank \#4 has the highest rupture frequency because its location is at the center, and is vulnerable to be affected by the explosions of the surrounding tanks.

Table 7. Frequency of domino events for each tank owing to a seismic event (E-06/year)

\begin{tabular}{c|c|c|c|c|c|c|c|c|c|c|c}
\hline \hline Tank \# (i) & 1 & 2 & 3 & 4 & 5 & 6 & 7 & 8 & 9 & 10 & 11 \\
\hline$D_{i}$ & 0.7 & 0.9 & 0.7 & 0.9 & 0.9 & 0.9 & 0.9 & 0.6 & 0.6 & 0.6 & 0.6 \\
& 0 & 8 & 0 & 9 & 9 & 0 & 0 & 6 & 6 & 5 & 5 \\
\hline
\end{tabular}

A catastrophic rupture scenario of saturated liquid at $278.15 \mathrm{~K}$ for all tanks was also selected from Phast-Risk ver. 6.7. The population was assumed to be 8100 within an area of 2,639,939 $\mathrm{m}^{2}$. The fraction of the indoor population is 0.1 , and that of the outdoor population is 0.9 . Owing to an immediate ignition, explosions are assumed to be $30 \%$ of the catastrophic rupture events, and the other $70 \%$ are the consequences of a flash fire. The vulnerability of people in an indoor area to a flash fire is assumed to be $10 \%$, and is $100 \%$ for people outdoors. A total of 18 wind directions were properly input based on their probabilities using a wind rose for more than a 30year period at a nearby airport, as shown in Table 8; in addition, for the weather conditions, a 1.5 $\mathrm{m} / \mathrm{s}$ wind speed and air stability class F (stable) were chosen, as in the previous QRA study, for a conservative approach. The distances between tanks are shown in Table 9. Calculated for the tank, BLEVE, 3 barg of overpressure is observed for up to $45 \mathrm{~m}$, and no tank is farther than $28 \mathrm{~m}$ from another tank, as shown in the table, which means an explosion from a tank should affect the nearby tanks. For the domino effect, the tanks are located quite close to each other, making it unlikely for them to be unaffected if an explosion occurs at a nearby tank.

Table 8. Wind direction probability at the event location

\begin{tabular}{|c|c|c|c|c|c|}
\hline $\begin{array}{c}\text { Wind direction } \\
\left({ }^{\circ}\right)\end{array}$ & $\%$ & $\begin{array}{c}\text { Wind direction } \\
\left({ }^{\circ}\right)\end{array}$ & $\%$ & $\begin{array}{c}\text { Wind direction } \\
\left({ }^{\circ}\right)\end{array}$ & $\%$ \\
\hline $350-10$ & 8.4 & $110-130$ & 4.4 & $230-250$ & 3.3 \\
\hline $10-30$ & 11.2 & $130-150$ & 5.9 & $250-270$ & 2.3 \\
\hline $30-50$ & 8.7 & $150-170$ & 6.3 & $270-290$ & 2.8 \\
\hline $50-70$ & 4.8 & $170-190$ & 5.1 & $290-310$ & 5.4 \\
\hline $70-90$ & 3.9 & $190-210$ & 4.4 & $310-330$ & 8.2 \\
\hline $90-110$ & 3.4 & $210-230$ & 4.7 & $330-350$ & 6.8 \\
\hline
\end{tabular}


Table 9. Distance matrix for the center of one tank to the center of another tank (m)

\begin{tabular}{|c|c|c|c|c|c|c|c|c|c|c|c|}
\hline Tank & 1 & 2 & 3 & 4 & 5 & 6 & 7 & 8 & 9 & 10 & 11 \\
\hline 1 & - & 25 & 50 & 32 & 52 & 56 & 70 & 77 & 90 & 24 & 47 \\
\hline 2 & - & - & 25 & 31 & 34 & 52 & 56 & 75 & 78 & 34 & 31 \\
\hline 3 & - & - & - & 46 & 31 & 61 & 52 & 82 & 76 & 54 & 28 \\
\hline 4 & - & - & - & - & 28 & 23 & 39 & 46 & 57 & 56 & 62 \\
\hline 5 & - & - & - & - & - & 31 & 24 & 51 & 46 & 67 & 55 \\
\hline 6 & - & - & - & - & - & - & 28 & 22 & 37 & 78 & 83 \\
\hline 7 & - & - & - & - & - & - & - & 36 & 23 & 89 & 79 \\
\hline 8 & - & - & - & - & - & - & - & - & 28 & 101 & 105 \\
\hline 9 & - & - & - & - & - & - & - & - & - & 110 & 103 \\
\hline 10 & - & - & - & - & - & - & - & - & - & - & 38 \\
\hline
\end{tabular}

Inputting all frequencies, process conditions, and weather conditions, the yellow FN curve shown in Fig. 7 appears. The blue line is the original FN curve, which does not consider either a seismic or a domino effect. The yellow line, in contrast, includes all factors. Fig. 7 explicitly shows that a difference mainly occurs for the frequency. For the consequences, however, the numbers of fatalities do not differ owing to the limitation of the program, which counts each tank rupture independently such that the maximum value of $\mathrm{N}$ is always the same. In fact, there should be little difference in the numbers of fatalities because the tanks are so close to each other that the fatality zones are similar and overlap.

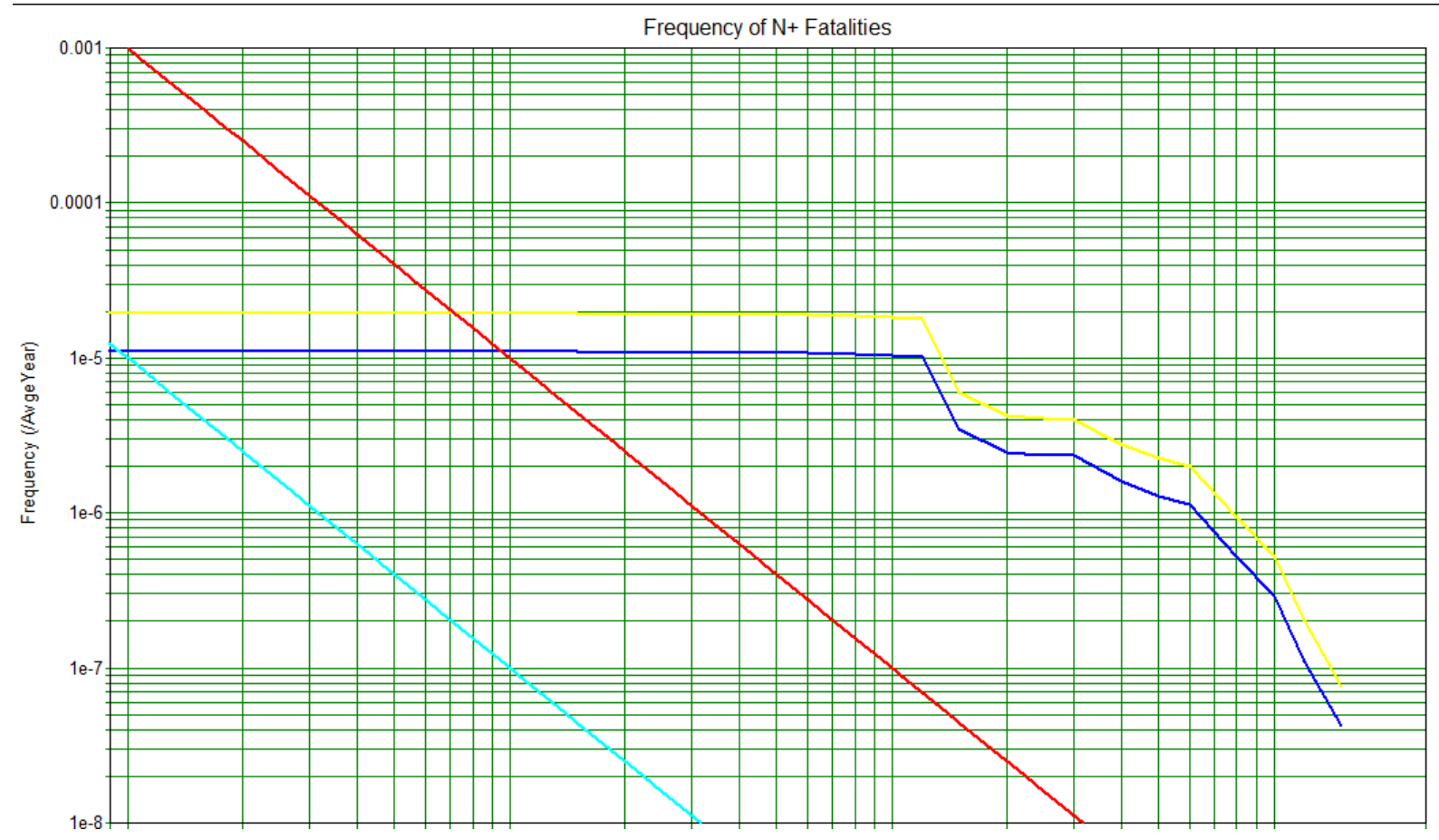


Fig. 7. Comparison of FN curves

Red line: maximum risk criteria

Sky blue line: minimum risk criteria

Blue line: original FN curve

Yellow line: FN curve considering a domino effect from a seismic event

\section{Conclusion}

Events and accidents related to multiple units in the nuclear and chemical industry have been explored because too many units with a substantial hazard risk are foreseen to be more dangerous than in a plant with fewer units or only one. Therefore, this study attempted to determine how risks could differ between the original QRA study and a QRA study that considers a seismic event and a subsequent domino effect, particularly when there are too many large-sized tanks located very close at a particular site. The frequency of seismic events for a certain LPG storage location in South Korea was applied, along with the weather conditions and population. Phast-Risk ver. 6.7 was employed to swiftly generate FN curves for a seismic event combined with a domino effect. Definitive increments in frequency were observed in the FN curve when compared with the original FN curve without a domino effect. This research can help the nuclear industry as solid evidence indicating that multi-unit plants have a higher risk than single-unit plants, which lack the possibility of a direct domino event.

\section{Acknowledgments}

This work was supported by the Nuclear Safety Research Program through the Korea Radiation Safety Foundation (KORSAFe), granted financial resource from the Nuclear Safety and Security Commission (NSSC), Republic of Korea (No. 1403003).

\section{References}

1. Oh, K., Heo, G. \& Jang, S.,Survey on challenging issues of multi-unit PSA, Transactions of the Korean Nuclear Society Autumn Meeting, Pyeongchang, Oct. 2014

2. Schroer, S., Modarres, M.,An event classification schema for evaluating site risk in a multi-unit nuclear power plant probabilistic risk assessment, Reliability Engineering and system Safety. 2013; 117, 40-51.

3. Hakata, T., Seismic PSA method for multiple nuclear power plants in a site. Reliability Engineering and system Safety 2007; 92, 883-894.

4. Giovanni, F., Iervolino, I., Orlando, F. \& Salzano, E. Quantitative risk analysis of oil storage facilities in seismic areas, Journal of Hazardous Materials 2005; 61-69

5. Akatsuka, H. \& Kobayashi, H. Failure knowledge database. Retrieved from http://www.sozogaku.com/fkd/en/cfen/CB1012035.html 2015, Mar

6. The 100 Largest Losses 1972-2001, Large Property Damage Losses in the HydrocarbonChemical Industries. 20th Edition: February 2003, Marsh’s Risk Consulting Practice

7. Hindmarsh, R., Nuclear Disaster at Fukushima Daiichi: Social, Political and Environmental Issues 2013; pp. 46

8. Kardell, L. \& Lööf, M. QRA with respect to domino effects and property damage 2014 
9. Antonioni, G., G. Spadoni, and V. Cozzani, A methodology for the quantitative risk assessment of major accidents triggered by seismic events. Journal of hazardous materials, 2007. 147(1-2): p. 48-59.

10. T. Kang, Risk Analysis of industrial accidents for public safety, Kwangwoon Univ. Seoul, 1999

11. Rhee H., Seo J., Sheen D. \& Choi I., Probabilistic Seismic Hazard Analysis on Metropolitan Cities and Counties in Korea. Journal of the Geological Society of Korea. 2012; 48, 3, pp. 259-273

12. Kim, H., Lee S., Park J., Kim H., Chang Y. \& Heo G., Reliability Data Update Using Condition Monitoring and Prognostics in PSA, Nuclear Engineering and Technology, 2015

13. Oh, K., Jung S., Heo G. \& Jang S., Technical issues of PSA for Korean multi-unit nuclear power plants, European Safety and Reliability Conference Annual meeting, Zurich, Sep. 2015 